\title{
Analysis of genes causing hypertension and stroke in spontaneously hypertensive rats: Gene expression profiles in the brain
}

\author{
MOMOKO YOSHIDA $^{1,2^{*}}$, YUKO WATANABE $^{1,2^{*}}$, KYOSUKE YAMANISHI $^{4,5}$, AKIFUMI YAMASHITA $^{2}$, \\ HIDEYUKI YAMAMOTO $^{5}$, DAISUKE OKUZAKI ${ }^{3}$, KAZUNORI SHIMADA $^{1}$, HIROSHI NOJIMA $^{3}$, \\ TERUO YASUNAGA ${ }^{2}$, HARUKI OKAMURA ${ }^{5}$, HISATO MATSUNAGA ${ }^{4}$ and HIROMICHI YAMANISHI ${ }^{1}$ \\ ${ }^{1}$ Hirakata General Hospital for Developmental Disorders, Hirakata, Osaka 573-0122; ${ }^{2}$ Department of Genome Informatics and \\ ${ }^{3}$ DNA-Chip Development Center for Infectious Diseases, Research Institute for Microbial Diseases, Osaka University, \\ Suita, Osaka 565-0871; ${ }^{4}$ Department of Neuropsychiatry and ${ }^{5}$ Institute for Advanced Medical Sciences, \\ Hyogo College of Medicine, Nishinomiya, Hyogo 663-8501, Japan
}

Received September 9, 2013; Accepted January 9, 2014

DOI: $10.3892 /$ ijmm.2014.1631

\begin{abstract}
Spontaneously hypertensive rats (SHR) and strokeprone SHR (SHRSP) are frequently used as rat models not only of essential hypertension and stroke, but also of attention-deficit hyperactivity disorder (ADHD). Normotensive Wistar-Kyoto rats (WKY) are used as the control rats in these cases. An increasing number of studies has demonstrated the critical role of the central nervous system in the development and maintenance of hypertension. In a previous study, we analyzed the gene expression profiles in the adrenal glands of SHR. Thus, in this study, we analyzed gene expression profiles in the brains of SHR in order to identify the genes responsible for causing hypertension and stroke, as well as those involved in ADHD. Using genome-wide microarray technology, we examined the gene expression profiles in the brains of 3 rat strains (SHR, SHRSP and WKY) when the rats were 3 and 6 weeks of age, a period in which the rats are considered to be in a prehypertensive state. Gene expression profiles in the brain were
\end{abstract}

Correspondence to: Dr Hiromichi Yamanishi, Hirakata General Hospital for Developmental Disorders, 2-1-1 Tsudahigashi, Hirakata, Osaka 573-0122, Japan

E-mail: hirochan@hirakataryoiku-med.or.jp

${ }^{*}$ Contributed equally

Abbreviations: ADHD, attention-deficit hyperactivity disorder; DAVID, Database for Annotation, Visualization and Integrated Discovery; FC, fold change; GEO, Gene Expression Omnibus; GO, Gene Ontology; IPA, Ingenuity Pathway Analysis; qRT-PCR, quantitative real-time polymerase chain reaction; SHR, spontaneously hypertensive rats; SHRSP, stroke-prone SHR; WKY, normotensive Wistar-Kyoto rats

Key words: attention-deficit hyperactivity disorder, brain, gene expression profiles, hypertension, spontaneously hypertensive rats, microarray, stroke-prone, normotensive Wistar-Kyoto rats compared between SHR and WKY, and between SHRSP and SHR. A total of 179 genes showing a $>4$ - or $<-4$-fold change in expression were isolated, and candidate genes were selected using two different web tools: the first tool was the Database for Annotation, Visualization and Integrated Discovery (DAVID), which was used to search for significantly enriched genes, and categorized them using Gene Ontology (GO) terms, and the second was the network explorer of Ingenuity Pathway Analysis (IPA), which was used to search for interaction networks among SHR- and SHRSP-specific genes. The IPA of SHR-specific genes revealed that prostaglandin E receptor 4 (Ptger4) is one of the candidate genes responsible for causing hypertension in SHR, and that albumin $(A l b)$ and chymase 1 (Cmal) are also responsible for causing hypertension in SHR in the presence of angiotensinogen $(A g t)$. Similar analyses of SHRSP-specific genes revealed that the angiotensin II receptorassociated gene (Agtrap) interacts with the FBJ osteosarcoma oncogene (Fos), and with the angiotensin II receptor type-1b (Agtrlb). As Agtrap and Agtrlb not only participate in the 'uptake of norepinephrine' and 'blood pressure', but also in the 'behavior' of SHRSP at 6 weeks of age, our data demonstrate a close association between hypertension and ADHD.

\section{Introduction}

Studies have been carried out to identify genes causing hypertension using 2 strains of hypertensive rats: spontaneously hypertensive rats (SHR) and a substrain derived from SHR, stroke-prone SHR (SHRSP) (1,2). Normotensive Wistar-Kyoto rats (WKY) are normally used as the control rats (1). Since SHR and SHRSP are not only used as rat models of essential hypertension and stroke, but also as rat models of attentiondeficit hyperactivity disorder (ADHD), studies using these rat models are expected to reveal genes not only related to hypertension and stroke, but also those related to ADHD (3-6). In a previous study, as the first step of this project, we investigated gene expression profiles in adrenal glands in these 3 rats strains when the rats were 3 and 6 weeks of age (7). 
An increasing number of studies has demonstrated the critical role of the central nervous system in the development and maintenance of hypertension and brain ventricular enlargement, accompanied by the loss of brain tissue and weight, as well as in the volume of grey matter $(8,9)$. In this study, as a second step in identifying genes responsible for causing hypertension and stroke, as well as those related to ADHD, we compared gene expression profiles in the brains of 3 rat strains, between SHR and WKY, and between SHRSP and SHR. When the rats were at 3 and 6 weeks of age, a period in which the rats are considered to be in a pre-hypertensive state, a total of 179 genes presenting a $>4$ - or $<-4$-fold change in expression were isolated.

After classifying the 179 genes according to their expression profiles, candidate genes were selected as significantly enriched genes, and categorized with Gene Ontology (GO) terms using the Database for Annotation, Visualization and Integrated Discovery (DAVID) web tools $(10,11)$. Subsequently, the interactions of these genes were analyzed with Ingenuity Pathway Analysis (IPA). IPA of SHR-specific genes revealed that prostaglandin E receptor 4 (Ptger4) is one of the candidate genes responsible for causing hypertension in $\operatorname{SHR}(12,13)$, as well as albumin (Alb) and chymase $1(\mathrm{Cmal})$, in the presence of angiotensinogen (Agt) (14-16). Similar analyses of SHRSPspecific genes revealed that angiotensin II receptor-associated gene (Agtrap) interacts with FBJ osteosarcoma oncogene (Fos), and with angiotensin II receptor type-1B (Agtrlb) (17-19). These interactions play pivotal roles among SHRSP-specific genes, and since Agtrap and Agtrlb not only participate in the 'uptake of norepinephrine' and 'blood pressure', but also in the 'behavior' of 6-week-old SHRSP, the data presented in the present study reveal a close association between hypertension and ADHD.

\section{Materials and methods}

Animals, RNA extraction, microarray design, microarray analysis and microarray data analysis. The details of these procedures have been described in our previous study [Yamamoto et al (7)].

Animals. The animals used in this study, SHR/Izm, SHRSP/ Izm and WKY/Izm, were provided by the Disease Model Cooperative Research Association, Kyoto, Japan. Threeweek-old rats were purchased and maintained for 2 days in our animal facility and used as 3-week-old rats. Five-week-old rats were purchased and, after having been maintained for 1 week in our animal facility, were used as 6-week-old rats. All the animals were handled according to the guidelines established by the Japanese Association for Laboratory Animal Science, while all experiments involving rats were approved by the Animal Care and Use Committee of Hyogo College of Medicine on September 27, 2010.

RNA extraction. Briefly, total RNA was purified using an miRNeasy kit (Qiagen, Hilden, Germany) according to the manufacturer's instructions.

Microarray design. Expression profiling was performed using the $4 \mathrm{x} 44 \mathrm{~K}$ whole rat genome oligo microarray version 3.0
G2519F (Agilent Technologies Inc., Santa Clara, CA, USA). Eighteen 1-color microarray-based gene analyses were performed with WKY, SHR and SHRSP at 3 and 6 weeks of age as biological triplicates. Each gene expression profile was compared between SHR and WKY, as well as between SHRSP and SHR at 3 and 6 weeks of age.

Microarray analysis. Total RNA (200 ng) was reversetranscribed into double-stranded cDNA using AffinityScript multiple temperature reverse transcriptase, and amplified. The resulting cRNA were labeled with cyanine-3-labeled cytosine triphosphate (Perkin-Elmer, Wellesley, MA, USA) using a Low Input Quick-Amp Labeling kit (Agilent Technologies Inc.). The labeled samples were hybridized with Agilent $4 \times 44 \mathrm{~K}$ whole rat genome arrays (Agilent Design \#028282). After washing, the slides were scanned with an Agilent Microarray Scanner (G2505C). Feature extraction software (version 10.5.1.1) was used to convert the images into gene expression data.

Microarray data analysis. Raw data were imported into Subio platform version 1.12 (Subio Inc., Aichi, Japan), and raw intensity data were normalized to the 75th percentile intensity of probes above background level (gIsWellAbove=1). SHRand SHRSP-specific genes were defined as those showing signal ratios with a $>4$ - or $<-4$-fold change in expression. Raw data were accepted in Gene Expression Omnibus (GEO, accession no. GSE41452).

Quantitative real-time polymerase chain reaction ( $q R T-P C R)$. To validate the results obtained by microarray analysis, 6 enriched genes were randomly selected from 27 unique enriched genes, and qRT-PCR was performed under 10 different experimental conditions. Total RNA (10 ng/reaction) extracted from WKY, SHR and SHRSP, was analyzed using the One-step qPCR kit (RNA-direct SYBR-Green Real-Time PCR Master Mix; Toyobo, Tokyo, Japan). Samples were run in duplicate reactions in 96-well plates, as previously described (20). Median threshold cycle values were used to calculate the fold change (FC) values between SHR and WKY, and between the SHRSP and SHR reference samples. The FC values were normalized to GAPDH levels. The following temperature profile was used: $30 \mathrm{sec}$ at $90^{\circ} \mathrm{C}$ and $20 \mathrm{~min}$ at $61^{\circ} \mathrm{C}$ for reverse transcription according to the manufacturer's instructions, followed by 45 cycles at $95^{\circ} \mathrm{C}$ for $15 \mathrm{sec}, 65^{\circ} \mathrm{C}$ for $15 \mathrm{sec}$, and $74^{\circ} \mathrm{C}$ for $35 \mathrm{sec}$. Statistical comparisons between microarray and qRT-PCR data were performed using Spearman's rank correlation test.

DAVID web tool analysis. An approach to annotation enrichment analysis was performed using DAVID (http://david.abcc. ncifcrf.gov/) web tools (version 6.7, 2010) $(10,11)$. This webbased resource provides a set of functional annotation tools for the statistical enrichment of genes classified based on GO terms. We used the GO FAT category, which filters out very broad GO terms to identify statistically enriched functional groups. The annotated gene and protein symbols are presented in italics and regular font, respectively.

IPA. IPA software (Ingenuity ${ }^{\circledR}$ Systems, http://www.ingenuity. com) was used for the functional interpretation of gene expres- 
Table I. Number and classification of SHR- and SHRSP-specific probes compared between the 2 pairs of rat strains.

\begin{tabular}{|c|c|c|c|c|c|}
\hline & \multicolumn{2}{|c|}{ SHR/WKY } & \multicolumn{2}{|c|}{ SHRSP/SHR } & \multirow[b]{2}{*}{ All } \\
\hline & $\begin{array}{c}\text { G-1 } \\
3 \text { weeks old }\end{array}$ & $\begin{array}{c}\mathrm{G}-2 \\
6 \text { weeks old }\end{array}$ & $\begin{array}{c}\text { G-3 } \\
3 \text { weeks old }\end{array}$ & $\begin{array}{c}\text { G-4 } \\
6 \text { weeks old }\end{array}$ & \\
\hline All probes isolated & 66 & 177 & 19 & 126 & 388 \\
\hline Mapped probes & 45 & 74 & 15 & 51 & 185 \\
\hline Unmapped probes & 21 & 103 & 4 & 75 & 203 \\
\hline Identified unique genes & 42 & 73 & 14 & 50 & 179 \\
\hline Upregulated & 14 & 51 & 8 & 8 & 81 \\
\hline Downregulated & 28 & 22 & 6 & 42 & 98 \\
\hline Enriched GO terms & 3 & 2 & $1^{\mathrm{a}}$ & 3 & 9 \\
\hline Enriched genes & 12 & 10 & 2 & 11 & 35 \\
\hline
\end{tabular}

Number of SHR- and SHRSP-specific probes isolated from the brain as described in Materials and methods; 179 of the 388 isolated probes corresponded to unique genes with Entrez IDs. Using DAVID web tools, 179 unique genes were categorized based on GO terms, from which 35 were identified as enriched

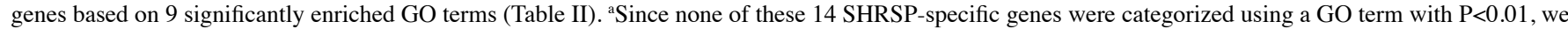
exceptionally categorized 2 of them into GO:0008015 (blood circulation) with P=0.068 (Table II, G-3). SHR, spontaneously hypertensive rats; SHRSP, strokeprone SHR; WKY, Wistar-Kyoto rats; GO, Gene Ontology.

sion data obtained from microarray analyses. The network explorer of IPA was used to identify relevant interactions among SHR- and SHRSP-specific genes, and to identify the shortest literature-supported paths between genes. This web tool was also used to overlay functions and diseases, and to categorize SHR- and SHRSP-specific genes by classifying them based on the disease-related functional annotations. IPA also identified the biological functions and/or diseases in the Ingenuity Knowledge Base that were most significant to each of the category sets. The level of support for the assignment was expressed by P-values calculated using the right-tailed Fisher's exact test.

\section{Results}

Identification and classification of SHR- and SHRSP-specific genes. Since we expected the expression levels of the candidate genes to be regulated long before the increase in blood pressure occurred, i.e., during the pre-hypertensive period, we examined the expression profiles of each probe using RNA samples prepared from brain tissue obtained from rats at 3 and 6 weeks of age, and isolated a total of 388 SHR- and SHRSPspecific probes showing a $>4$ - or $<-4$-fold change in expression (Table I).

We classified 388 probes into 4 groups (G-1 to $G-4$ ) depending on the 2 rat strain pairs (SHR/WKY and SHRSP/ SHR) and their age (Table I) as follows: G-1 probes were isolated when the rats were 3 weeks of age and contained 66 SHR-specific probes. These 66 probes corresponded to 42 unique genes: 14 of them showed a $>4$-fold increase, and 28 showed a $<-4$-fold decrease in expression. G-2 contained 73 SHR-specific unique genes isolated when the rats were 6 weeks of age. G-3 contained 14 SHRSP-specific unique genes isolated when the rats were 3 weeks of age. G- 4 contained 50 SHRSP-specific genes isolated when the rats were 6 weeks of age. As shown in Table I, 388 probes were identified, representing 179 unique genes.
Isolation of candidate genes as significantly enriched genes. Firstly, candidate genes responsible for causing hypertension, stroke and ADHD were selected from each group as significantly enriched genes using DAVID $(10,11)$. We isolated a total of 35 enriched genes: G-1 contained 12 enriched genes categorized with $3 \mathrm{GO}$ terms, G-2 contained 10 enriched genes categorized with 2 GO terms, G-3 contained 2 enriched genes categorized with $1 \mathrm{GO}$ term, and G-4 contained 11 enriched genes categorized with $3 \mathrm{GO}$ terms (Table I).

These 35 enriched genes consisted of 27 unique genes (Table II). To verify the results obtained by microarray analyses, we randomly selected 6 out of the 27 genes (Table III-A), performed 10 qRT-PCR experiments (Table III-B), and compared the results with those of obtained from microarray analyses by applying Spearman's rank correlation test. The results supported the significant correlation between qRT-PCR and microarray analyses, showing an rs value of 0.697 with a two-tailed $\mathrm{P}$-value of 0.025 .

Categorization of enriched genes. Enriched G-1 genes were categorized into 3 GO terms: i) GO:0051657 (maintenance of organelle location) included 2 genes: LOC501349 and Alb (Table II, G-1). Alb was also categorized into GO:0008015 (blood circulation) (Table II, G-2); ii) GO:0047760 (butyrateCoA ligase activity) included 2 genes: acyl-CoA synthetase medium-chain family 5 and 2 (Acsm5 and Acsm2, respectively); and iii) GO:0005576 (extracellular region) included 8 genes: $\mathrm{Cmal}$, vascular endothelial growth factor B (Vegfb), $\alpha$-fetoprotein (LOC360919), collagen-like tail subunit of asymmetric acetylcholine-esterase (Colq), chitinase 3-like 1 (Chi3l1), $\alpha$-amylase 1 (Amyla), sparc/osteonectin (Spock2) and glycoprotein hormones $\alpha$ chain $(\mathrm{Cga})$ (Table II, G-1).

Enriched G-2 genes were categorized into 2 GO terms: i) GO:0008015 (blood circulation) included 5 genes: Agtrap, glutamate-cysteine ligase modifier subunit (Gclm), Agtrlb, $A l b$, and epoxide hydrolase 2 (Ephx2); and ii) GO:0006952 (defense response) included 5 genes: C-X-C motif chemo- 
Table II. Classification and enrichment of SHR- and SHRSP-specific genes.

\begin{tabular}{|c|c|c|c|c|c|c|c|}
\hline Group & GO category & GenBank ID & Description & GS & FC & P-value & Refs. \\
\hline \multirow[t]{12}{*}{ G-1 } & \multirow{2}{*}{$\begin{array}{l}\text { GO:0051657 }(\mathrm{P}=0.009) \text {, } \\
\text { maintenance of } \mathrm{OL}^{\mathrm{a}}\end{array}$} & XM_001073636 & Hypothetical LOC501349 & LOC501349 & -4.4 & 0.001 & \\
\hline & & NM_134326 & Albumin & $A l b$ & -12.4 & 0.000 & $(15)$ \\
\hline & \multirow[t]{2}{*}{$\begin{array}{l}\text { GO:0047760 }(\mathrm{P}=0.010), \\
\text { butyrate-CoA ligase activity }\end{array}$} & NM_001014162 & $\begin{array}{l}\text { Acyl-CoA synthetase } \\
\text { medium-chain family } 5\end{array}$ & Acsm5 & 5.3 & 0.005 & $(32,33)$ \\
\hline & & NM_144748 & $\begin{array}{l}\text { Acyl-CoA synthetase } \\
\text { medium-chain family } 2\end{array}$ & $\operatorname{Acsm} 2$ & -4.5 & 0.004 & $(32,33)$ \\
\hline & \multirow{8}{*}{$\begin{array}{l}\text { GO:0005576 }(\mathrm{P}=0.011) \text {, } \\
\text { extracellular region }\end{array}$} & NM_013092 & Chymase 1 & Cmal & 7.4 & 0.008 & (16) \\
\hline & & NM_053549 & Vascular endothelial growth factor B & $V e g f b$ & -732.5 & 0.000 & (34) \\
\hline & & NM_001108356 & $\alpha$-fetoprotein & LOC360919 & -4.2 & 0.000 & \\
\hline & & NM_019274 & $\begin{array}{l}\text { Collagen-like tail asubunit of } \\
\text { asymmetric ACHE }\end{array}$ & Colq & -4.1 & 0.000 & $(35)$ \\
\hline & & NM_053560 & Chitinase 3 -like 1 & Chi3ll & 4.2 & 0.000 & $(36)$ \\
\hline & & NM_001010970 & $\alpha$-amylase 1 & Amyla & -5.2 & 0.009 & $(23,24)$ \\
\hline & & NM_001108533 & Sparc/osteonectin & Spock2 & 10.1 & 0.000 & (37) \\
\hline & & NM_053918 & Glycoprotein hormones $\alpha$-chain & $C g a$ & 16.5 & 0.007 & (38) \\
\hline \multirow[t]{10}{*}{ G-2 } & \multirow{5}{*}{$\begin{array}{l}\text { GO:0008015 }(\mathrm{P}=0.002) \text {, } \\
\text { blood circulation }\end{array}$} & NM_001007654 & Angiotensin II receptor-associated protein & Agtrap & -23.6 & 0.000 & (17) \\
\hline & & NM_017305 & Glutamate-cysteine ligase modifier subunit & Gclm & 5.4 & 0.001 & (39) \\
\hline & & NM_031009 & Angiotensin II receptor type-1B & Agtrlb & 5.8 & 0.000 & (19) \\
\hline & & NM_134326 & Albumin & $A l b$ & -9.2 & 0.001 & (15) \\
\hline & & NM_022936 & Epoxide hydrolase 2 & Ephx2 & -13.9 & 0.003 & $(40)$ \\
\hline & \multirow{5}{*}{$\begin{array}{l}\text { GO:0006952 }(\mathrm{P}=0.002) \text {, } \\
\text { defense response }\end{array}$} & NM_138522 & $\mathrm{C}-\mathrm{X}-\mathrm{C}$ motif chemokine 3 & Cxcl3 & -10.7 & 0.001 & $(41)$ \\
\hline & & NM_001128494 & Lysozyme $\mathrm{C}$ type 2 & $L y c 2$ & 5.1 & 0.001 & \\
\hline & & NM_012950 & Coagulation factor II receptor & $F 2 r$ & 5.3 & 0.001 & $(42)$ \\
\hline & & NM_001037534 & Defensin $\beta 17$ & Defbl7 & 88.4 & 0.000 & \\
\hline & & NM_019169 & $\alpha$-synuclein & Snca & 10.8 & 0.001 & $(26,27)$ \\
\hline \multirow[t]{2}{*}{ G-3 } & \multirow{2}{*}{$\begin{array}{l}\text { GO:0008015 }(\mathrm{P}=0.068) \text {, } \\
\text { blood circulation }\end{array}$} & NM_001007654 & Angiotensin II receptor-associated protein & Agtrap & -16.6 & 0.000 & (17) \\
\hline & & NM_022936 & Epoxide hydrolase 2 & Ephx2 & -15.1 & 0.000 & $(40)$ \\
\hline \multirow[t]{11}{*}{ G-4 } & \multirow{6}{*}{$\begin{array}{l}\text { GO:0042592 }(\mathrm{P}=0.004) \text {, } \\
\text { homeostatic process }\end{array}$} & XM_002725502 & Similar to paired-Ig-like receptor A11 & LOC690948 & 4.6 & 0.000 & \\
\hline & & NM_212504 & Heat shock $70-\mathrm{kDa}$ protein $1 \mathrm{~B}$ & Hspalb & -4.9 & 0.000 & $(31)$ \\
\hline & & NM_053633 & Early growth response 2 & Egr2 & -5.3 & 0.000 & $(29,30)$ \\
\hline & & NM_001037357 & Leukocyte IG-like receptor B3-like & Lilrb3l & 25.7 & 0.000 & $(43)$ \\
\hline & & NM_012654 & Solute carrier family 9 member 3 & Slc9a3 & -4.0 & 0.009 & (44) \\
\hline & & NM_019169 & $\alpha$-synuclein & Snca & -9.4 & 0.000 & $(26,27)$ \\
\hline & \multirow{4}{*}{$\begin{array}{l}\text { GO:0008015 }(\mathrm{P}=0.005) \text {, } \\
\text { blood circulation }\end{array}$} & NM_001007654 & Angiotensin II receptor-associated protein & Agtrap & 23.7 & 0.000 & (17) \\
\hline & & NM_017305 & Glutamate cysteine ligase modifier subunit & Gclm & -5.0 & 0.008 & (39) \\
\hline & & NM_031009 & Angiotensin II receptor type-1B & Agtrlb & -5.9 & 0.001 & (19) \\
\hline & & NM_022936 & Epoxide hydrolase 2 & Ephx2 & 12.6 & 0.000 & $(40)$ \\
\hline & $\begin{array}{l}\text { GO:0048168 }(\mathrm{P}=0.005) \\
\text { reg. of synaptic plasticity }\end{array}$ & NM_019361 & $\begin{array}{l}\text { Activity-regulated cytoskeleton-associated } \\
\text { protein }\end{array}$ & $A r c$ & -4.6 & 0.000 & (28) \\
\hline
\end{tabular}

SHR- and SHRSP-specific genes were classified into 4 groups (Table I). Members of each group were further categorized with GO terms using DAVID web tools, and genes with significantly enriched GO terms $(\mathrm{P}<0.01)$ were identified. In the case where one gene was categorized using more than one GO term within the same group, one GO term was arbitrarily assigned to the gene. ${ }^{a}$ Maintenance of OL, maintenance of organelle location; ${ }^{b}$ reg. of synaptic plasticity, regulation of neuronal synaptic plasticity; ACHE, acetylcholinesterase; GS, gene symbol; FC, fold change of $>4$-fold upregulation and <-4-fold downregulation; SHR, spontaneously hypertensive rats; SHRSP, stroke-prone SHR; GO, Gene Ontology.

kine 3 (Cxcl3), lysozyme C type 2 (Lyc2), coagulation factor II receptor $(F 2 r)$, defensin $\beta 17$ (Defb17) and $\alpha$-synuclein (Snca) (Table II, G-2).

Enriched G-3 genes included Agtrap and Ephx2, which were categorized into GO:0008015 (blood circulation).
These 2 genes were also categorized as enriched G-2 genes (Table II, G-2). Enriched G-4 genes were categorized into 3 GO terms: i) GO:0042592 (homeostatic process) included 6 genes: similar to paired-immunoglobulin-like receptor A11 (LOC690948), heat shock 70-kDa protein 1B (Hspalb), early 
Table III. Validation of microarray data with qRT-PCR data.

A, Primers used for qRT-PCR experiments

\begin{tabular}{|c|c|c|}
\hline Gene symbol & Forward primer $\left(5^{\prime}-3^{\prime}\right)$ & Reverse primer $\left(5^{\prime}-3^{\prime}\right)$ \\
\hline$V e g f b$ & TACCTGCAGATCATCAGAAACTTAGCTC & CTCTCACCATCTGATTTGTGCAT \\
\hline Defb17 & CCCGACTACAAAACAAACTGACT & TCCTTTTGCCTGTTAGTATTGTGATCGAA \\
\hline Agtrap & AAGCCCAAGATGTTTTCTCGT & CTTCCTTCCGACAAGAACCCT \\
\hline Ephx2 & AGGCCCTCTAAACTGGTATCGAA & АТСTTCСTTCCCAACGCCTT \\
\hline Lilrb3l & GCCСТTTGACCTCCAACCAG & GTTCACTAGGAGCTGACCACAC \\
\hline LOC690948 & ATGTTATGGTTACTACAAGAATACCCCACA & ATGGCTTCCTCAATGGTCCT \\
\hline
\end{tabular}

B, Data used for Spearman's correlation analysis

\begin{tabular}{lllrl}
\hline Group & GenBank ID & Gene symbol & FC (qRT-PCR) & FC (microarray) \\
\hline G-1 & NM_053549 & Vegfb & -10.915 & -732.490 \\
G-2 & NM_001007654 & Agtrap & 1.603 & -16.619 \\
G-2 & NM_001037534 & Defb17 & 3.402 & 98.601 \\
G-2 & NM_022936 & Ephx2 & -3.794 & -15.072 \\
G-3 & NM_001007654 & Agtrap & -1.115 & -23.563 \\
G-3 & NM_022936 & Ephx2 & -3.310 & -13.898 \\
G-4 & NM_001007654 & Agtrap & 1.324 & 23.702 \\
G-4 & NM_022936 & Ephx2 & 3.028 & 12.647 \\
G-4 & NM_001037357 & Lilrb3l & 3.414 & 25.717 \\
G-4 & XM_002725502 & LOC690948 & 6.823 \\
\hline
\end{tabular}

qRT-PCR, quantitative real-time polymerase chain reaction; FC (qRT-PCR), fold change based on the results obtained with qRT-PCR; FC (microarray), fold change based on the results obtained with microarray analyses.

growth response 2 (Egr2), leukocyte immunoglobulin-like receptor B3-like (Lilrb3l), solute carrier family 9 member 3 (Slc9a3) and Snca; ii) GO:0008015 (blood circulation) included 4 genes: Agtrap, Gclm, Agtrlb and Ephx2; and iii) GO:0048168 (regulation of neuronal synaptic plasticity) included 1 gene: activity-regulated cytoskeleton-associated protein (Arc) (Table II, G-4).

Interactions among SHR-specific genes. We found that the G-1 genes did not include most of the hypertension-related genes, and that the G-2 genes included typical hypertensionrelated genes, such as Agtrap, Gclm, Agtrlb and Ephx2 (Table II, G-2). As these results suggested that G-1 genes included regulatory genes that control the expression of hypertension-related G-2 genes, we searched for interaction networks between G-1 and G-2 genes, using IPA software, and identified 2 interaction networks, one between Ptfla and Amyla, and the other between Ptger4 and neutrophil cytosolic factor 2 (Ncf2) (Fig. 1). The former interaction was also observed among G-1 genes, and the latter was also observed among G-2 genes (Fig. 1). Of note, Ptfla and Ptger4 were not categorized with the enriched GO terms: Ptfla encodes a protein related to transcriptional regulation, and Ptger4 encodes a receptor related to the regulatory expression of several genes (Table IV-A). For each non-enriched gene that participated in either interaction or was self-controlled, relevant references are presented (Table IV).
Interactions among SHRSP-specific genes. Since we expected the candidate genes responsible for causing stroke in SHRSP to be included in the SHRSP-specific genes, we were interested in the interactions between the G-3 and G-4 genes (Fig. 2), and identified 2 interactions: Agtrap expression was observed in the rats at 3 and 6 weeks of age and seemed to interact with 2 genes whose expression was observed in the rats at 6 weeks of age, Agtrlb and Fos (Fig. 2). Moreover, Fos expression, observed in the rats at 6 weeks of age seemed to be self-controlled, and also showed interactions with Agtrap, Agtrlb, Gclm, Egr2, as well as with Snca via Hspalb (Fig. 2). Of note, Fos expression in the rats at 6 weeks of age seemed to control Egr2, Ephx2 and $N c f 2$ expression (Fig. 2), and seemed to play a pivotal role among the genes expressed in SHRSP at 6 weeks of age.

Functions and disease-related annotations of SHR- and SHRSP-specific genes. SHR- and SHRSP-specific genes were evaluated for biological relevance using IPA, and we identified significantly enriched 'Functions', such as molecular transport ('uptake of norepinephrine'), the cardiovascular system ('blood pressure') and 'behavior' (Table V).

G-1 genes included 3 SHR-specific genes involved in renal damage $[A l b$, cytochrome P450 2c11 (Cyp2c11), and solute carrier organic anion transporter family member $6 \mathrm{~b} 1$ (Slco6b1)], and 5 genes involved in cellular function and maintenance [Chi3ll, Cmal, leukocyte immunoglobulin-like receptor B3 (Lilrb3), lymphocyte antigen 75 (Ly75) and Ptger4] 


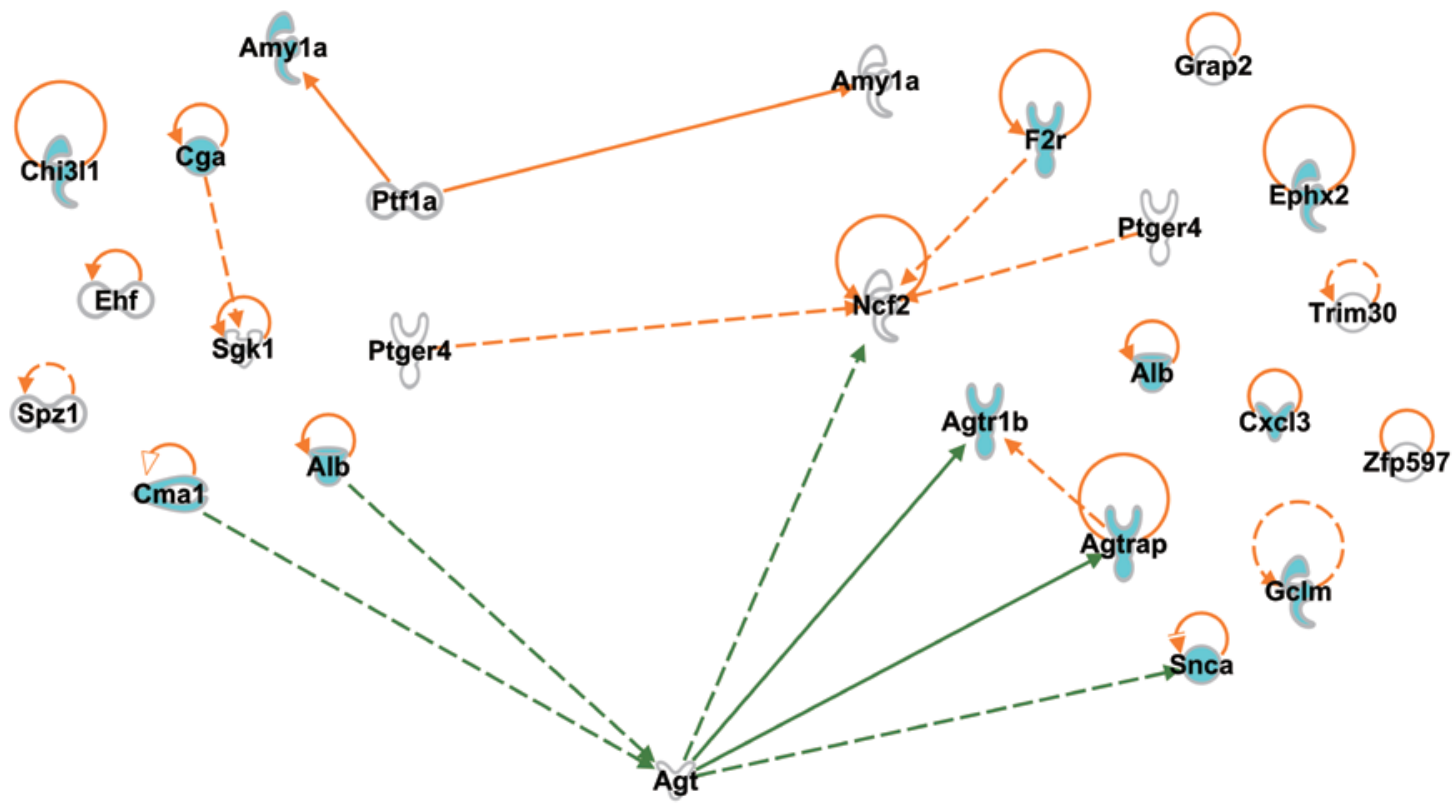

Figure 1. Analyses of interactions among SHR-specific genes. Interactions among SHR-specific genes isolated when the rats were 3 and 6 weeks of age were analyzed using Ingenuity Pathway Analysis (IPA). The figure shows the gene-to-gene correlations identified. Genes are represented as nodes and the biological relationship between 2 nodes is represented as an edge (line). Edges signify different correlations: solid lines represent direct interactions or associations, and dotted lines represent indirect interactions or associations. Nodes are displayed using various shapes that represent the functional class of the gene product (refer to IPA for detailed node information). The 10 nodes on the left represent SHR-specific genes isolated at 3 weeks of age, and the 14 nodes on the right represent SHR-specific genes isolated at 6 weeks of age. Interactions among SHR-specific genes are represented as orange edges. Interactions after postulating the presence of Agt function are represented as green edges. Nodes colored light blue represent enriched genes listed in Table II, and nodes without color are listed in Table IV-A. SHR, spontaneously hypertensive rats; SHRSP, stroke-prone SHR.

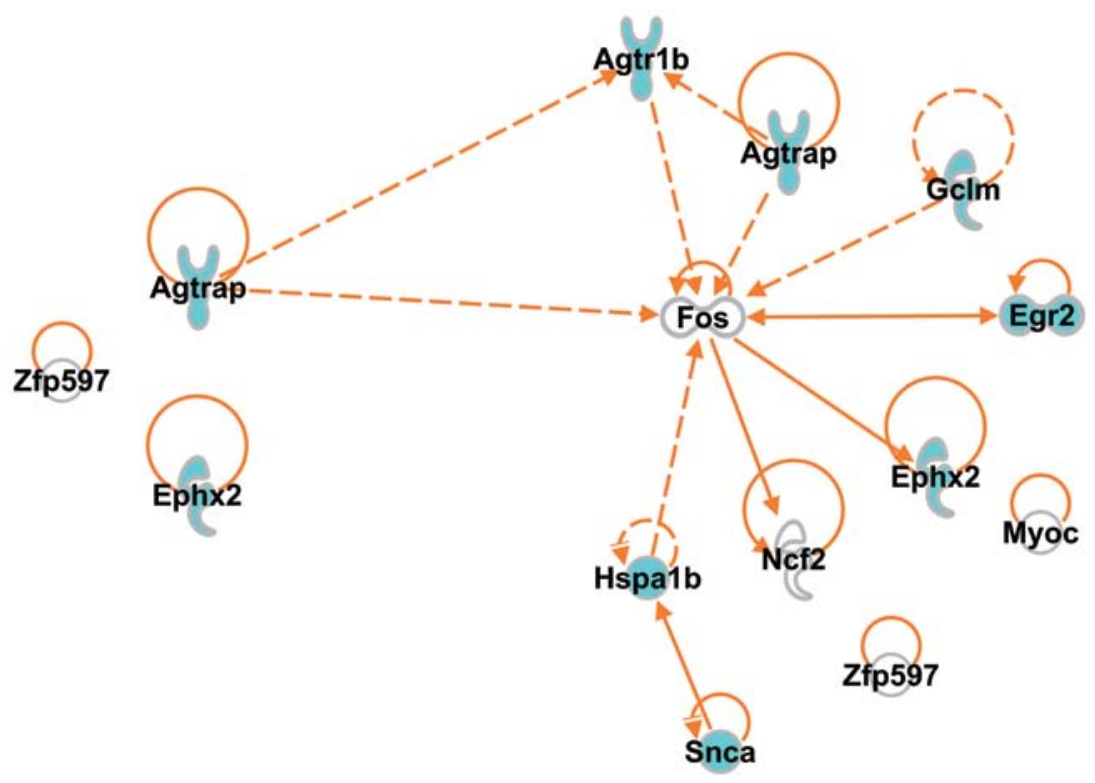

Figure 2. Analyses of interactions among SHRSP-specific genes. Interactions among SHRSP-specific genes isolated when the rats were at 3 and 6 weeks of age were analyzed using Ingenuity Pathway Analysis (IPA). The 3 nodes on the left correspond to SHRSP-specific genes isolated when the rats were 3 weeks of age, and the 11 nodes on the right correspond to SHRSP-specific genes isolated when the rats were 6 weeks of age. Nodes colored light blue represent enriched genes listed in Table II, and nodes without color are listed in Table IV-A. SHRSP, stroke-prone spontaneously hypertensive rats.

(Table V, G-1). Some of these G-1 genes, such as Cyp2c11, Slco6bl and $L y 75$, were not categorized into any of the enriched gene groups, nor into any of the groups of genes that participated in the interactions between geens (Table IV-B), and for each non-enriched gene evaluated for biological relevance, relevant references are provided. G-2 genes included 3 SHR-specific genes involved in the 'uptake of norepinephrine' (Agtrap, Agtrlb and Snca), and 5 genes involved with 
Table IV. List of non-enriched SHR- and SHRSP-specific genes.

\begin{tabular}{|c|c|c|c|c|c|c|}
\hline Group & GenBank ID & Description & GS & $\mathrm{FC}$ & P-value & Refs. \\
\hline \multirow[t]{5}{*}{ G-1 } & NM_001106493 & ETS homologous factor & Ehf & -5.0 & 0.003 & \\
\hline & NM_053964 & Pancreas-specific transcription factor 1a & Ptfla & 4.4 & 0.001 & $(21,22)$ \\
\hline & NM_032076 & Prostaglandin E receptor 4 & Ptger4 & -4.8 & 0.005 & $(12,13)$ \\
\hline & NM_019232 & Serum/glucocorticoid regulated kinase 1 & $S g k 1$ & 4.1 & 0.001 & $(45-47)$ \\
\hline & NM_001024297 & Spermatogenic leucine zipper 1 & Spzl & -4.1 & 0.004 & \\
\hline \multirow[t]{6}{*}{ G-2 } & NM_001010970 & $\alpha$-amylase 1 & Amyla & -5.4 & 0.009 & $(23,24)$ \\
\hline & NM_001034944 & GRB2-related adaptor protein 2 & Grap2 & -7.8 & 0.004 & \\
\hline & NM_001100984 & Neutrophil cytosolic factor 2 & $N c f 2$ & -4.3 & 0.000 & (25) \\
\hline & NM_032076 & Prostaglandin E receptor 4 & Ptger4 & -6.5 & 0.005 & $(12,13)$ \\
\hline & XM_574516 & Tripartite motif protein 30 -like & Trim30 & -4.7 & 0.000 & \\
\hline & NM_153732 & Zinc finger protein 597 & Zfp597 & 5.8 & 0.000 & (48) \\
\hline G-3 & NM_153732 & Zinc finger protein 597 & Zfp597 & 6.9 & 0.000 & $(48)$ \\
\hline \multirow[t]{4}{*}{ G-4 } & NM_022197 & FBJ osteosarcoma oncogene & Fos & -4.5 & 0.000 & (18) \\
\hline & NM_030865 & Myocilin & MyoC & 4.1 & 0.000 & \\
\hline & NM_001100984 & Neutrophil cytosolic factor 2 & $N c f 2$ & -4.3 & 0.000 & (25) \\
\hline & NM_153732 & Zinc finger protein 597 & Zfp597 & -7.0 & 0.000 & (48) \\
\hline
\end{tabular}

$\mathrm{B}$, Genes annotated to disease-related functions (Table V)

\begin{tabular}{|c|c|c|c|c|c|c|}
\hline Group & GenBank ID & Description & GS & $\mathrm{FC}$ & P-value & Refs. \\
\hline \multirow[t]{4}{*}{ G-1 } & NM_019184 & Cytochrome P450, subfamily 2, polypeptide 11 & Cyp2c11 & -6.7 & 0.003 & (49) \\
\hline & NM_031713 & Leukocyte immunoglobulin-like receptor B3 & Lilrb3 & -4.6 & 0.003 & (43) \\
\hline & NM_133412 & Solute carrier organic anion transporter family, member $6 \mathrm{~b} 1$ & Slco6bl & -7.2 & 0.002 & $(50)$ \\
\hline & XM_001068965 & Lymphocyte antigen 75 & Ly75 & 7.2 & 0.000 & $(51)$ \\
\hline \multirow[t]{6}{*}{ G-2 } & BC126094 & Coenzyme Q3 homolog, methyltransferase & $\operatorname{Coq} 3$ & 4.2 & 0.002 & $(52)$ \\
\hline & NM_001105859 & ST6-N-acetylgalactosaminide $\alpha$-2,6-sialyltransferase 1 & St6galnac1 & -6.0 & 0.007 & \\
\hline & NM_001105880 & Zinc finger and BTB domain containing 20 & Zbtb20 & 7.9 & 0.001 & (53) \\
\hline & NM_145770 & Acyl-Coenzyme A oxidase 2 & $\operatorname{Acox} 2$ & 5.3 & 0.000 & \\
\hline & XM_001068965 & Lymphocyte antigen 75 & Ly75 & 4.7 & 0.000 & $(51)$ \\
\hline & NM_001107541 & ADP-ribosyltransferase 1 & Art1 & -4.5 & 0.009 & \\
\hline \multirow[t]{2}{*}{ G-3 } & NM_019338 & Regulator of G-protein signaling 11 & $\operatorname{Rgs} 11$ & 5.0 & 0.000 & (54) \\
\hline & NM_053549 & Vascular endothelial growth factor B & $V e g f b$ & 768.1 & 0.000 & (33) \\
\hline \multirow[t]{2}{*}{ G-4 } & NM_001105880 & Zinc finger and BTB domain containing 20 & Zbtb20 & -10.8 & 0.000 & $(53)$ \\
\hline & NM_019338 & Regulator of G-protein signaling 11 & Rgs11 & -4.2 & 0.000 & (54) \\
\hline
\end{tabular}

SHR, spontaneously hypertensive rats; SHRSP, stroke-prone SHR; GS, gene symbol; FC, fold change of $>4$-fold upregulation and $<-4$-fold downregulation.

'blood pressure' (Agtrlb, Agtrap, Ephx2, F2r and $N c f 2$ ) (Table V, G-2). All these G-2 genes, apart from $N c f 2$, were categorized using enriched GO terms (Table II, G-2).

SHRSP-specific G-3 genes not only included Agtrap, involved in the 'uptake of norepinephrine', but also included Agtrap and Ephx2, which were involved in 'blood pressure' (Table V, G-3). SHRSP-specific G-4 genes included the following: i) 4 genes involved in the 'uptake of norepinephrine' (Agtrlb, Agtrap, Fos and Snca); ii) 4 genes involved in 'blood pressure' (Agtrlb, Agtrap, Ephx2 and Ncf2); and iii) 6 genes involved in the control of 'behavior' (Agtrlb, Arc, Egr2, Fos, Hspalb and Snca) (Table V, G-4). Although Fos and Ncf2 were not categorized using the enriched GO terms, the remaining SHRSP-specific genes involved in the 'uptake of norepinephrine', 'blood pressure' and/or in 'behavior', were categorized with the enriched GO terms, i.e., GO:0008015 (blood circulation) or GO:0042592 (homeostatic process) (Table II, G-4).

\section{Discussion}

The first aim of the current study was to identify the candidate genes responsible for causing hypertension in SHR, the second was to identify genes leading to stroke, and the third was to identify genes related to ADHD. Since juvenile SHRSP 
Table V. SHR- and SHRSP-specific genes classified based on the disease-related functional annotations.

\begin{tabular}{|c|c|c|c|c|}
\hline Group & IPA function (function and/or disease) & P-value & Gene symbol & Genes $^{\mathrm{a}}$ \\
\hline \multirow[t]{5}{*}{ G-1 } & Renal damage (proximal tubular toxicity) & 0.000 & Alb, Cyp2c11, Slco6b1 & 3 \\
\hline & Cell function and maintenance (function of leukocytes) & 0.001 & Chi3l1, Cma1, Lilrb3, Ly75, Ptger4 & 5 \\
\hline & Cellular development (arrest in differentiation of amacrine cells) & 0.001 & Ptfla & 1 \\
\hline & Neurological disease (delay in hyperalgesia) & 0.001 & $S g k 1$ & 1 \\
\hline & Developmental disorder (atresia) & 0.002 & $A l b, C g a$ & 2 \\
\hline \multirow[t]{7}{*}{ G-2 } & Molecular transport (uptake of norepinephrine) & 0.000 & Agtrap, Agtrlb, Snca & 3 \\
\hline & Carbohydrate metabolism (metabolism of carbohydrate) & 0.001 & $\begin{array}{l}\text { Agtr1b, Coq3, F2r, Ptger } 4, \text { Snca, } \\
\text { St6galnac1, Zbtb20 }\end{array}$ & 7 \\
\hline & Connective tissue disorders (rheumatoid arthritis) & 0.001 & Acox2, Alb, Art1, Cxcl3, Ephx2, Ptger4, Snca & 7 \\
\hline & Cell function and maintenance (proliferation of pro-T3 thymocytes) & 0.002 & Grap2 & 1 \\
\hline & Cell death (cell death of central nervous system cells) & 0.002 & Alb, Cxcl3, F2r, Gclm, Snca & 5 \\
\hline & Cardiovascular system (blood pressure) & 0.002 & Agtrap, Agtr1b, Ephx2, F2r, Ncf2 & 5 \\
\hline & Inflammatory response (inflammatory response) & 0.002 & Agtr1b, Cxcl3, Ephx2, F2r, Ly75, Ptger4, Snca & 7 \\
\hline \multirow[t]{6}{*}{ G-3 } & Lipid metabolism (quantity of 11,12-epoxyeicosatrienoic acid) & 0.000 & Ephx2 & 1 \\
\hline & $\begin{array}{l}\text { Nervous system development and function (delay in } \\
\text { photoresponse of mice) }\end{array}$ & 0.001 & Rgs 11 & 1 \\
\hline & Post-translational modification (O-glycosylation of protein) & 0.004 & $V e g f b$ & 1 \\
\hline & Cardiovascular system (blood pressure) & 0.004 & Agtrap, Ephx2 & 2 \\
\hline & Molecular transport (uptake of norepinephrine) & 0.004 & Agtrap & 1 \\
\hline & Cardiovascular system (development of cardiovascular system) & 0.024 & Ephx2, Vegfb & 2 \\
\hline \multirow[t]{7}{*}{ G-4 } & Molecular transport (uptake of norepinephrine) & 0.000 & Agtrap, Agtrlb, Fos, Snca & 4 \\
\hline & Organismal survival (survival of organism) & 0.000 & Agtr1b, Ephx2, Fos, Hspalb, Snca, Zbtb2O & 6 \\
\hline & Cell death (cytotoxicity) & 0.000 & Fos, Gclm, Hspalb, Snca & 4 \\
\hline & Molecular transport (reabsorption of bicarbonate) & 0.001 & Slc9a3 & 1 \\
\hline & Cardiovascular system (blood pressure) & 0.002 & Agtrap, Agtr1b, Ephx2, Ncf2 & 4 \\
\hline & Behavior (behavior) & 0.002 & Agtr1b, Arc, Egr2, Fos, Hspalb, Snca & 6 \\
\hline & Nervous system development and function (electrophysiology & 0.003 & Fos, Rgs11 & 2 \\
\hline
\end{tabular}

IPA was used to evaluate the biological relevance (functions annotation) of SHR- and SHRSP-specific genes. The results were obtained after having taken into consideration the P-values, and number of genes. GenBank gene symbols are shown for each gene. IPA, Ingenuity Pathway Analysis; SHR, spontaneously hypertensive rats; SHRSP, stroke-prone SHR.

present with a significant increase in motor activity, one of the typical symptoms of ADHD, as early as 6 weeks of age (3), we expected the genes isolated from the brain tissue of rats (SHR- or SHRSP-specific genes) at 3 and 6 weeks of age to include not only those related to hypertension and stroke, but also those related to ADHD.

Interactions among SHR-specific genes, and candidate genes responsible for causing hypertension in SHR. We found that G-1 genes included regulatory genes which control the expression of hypertension-related G-2 genes. We also identified interactions between G-1 and G-2 genes: one between Ptfla and Amyla, and another between Ptger4 and Ncf2 (Fig. 1). The first interaction (Ptfla and Amyla) affects carbohydrate metabolism, since Ptfla encodes a protein that is a component of the transcription factor complex (21,22), and Amyla encodes an amylase isoenzyme produced by the pancreas, which catalyzes the first step in the digestion of dietary starch and glycogen. However, its role in the genesis of hypertension is not clear at present $(23,24)$. On the other hand, the interaction between Ptger4 and Ncf2 is expected to affect blood pressure, as Ncf2 was functionally involved in 'blood pressure' (Table V, G-2).
Ptger4 encodes a member of the G-protein coupled receptor family, and leads to the phosphorylation of glycogen synthase kinase-3, which can act as a regulatory switch for numerous signaling pathways involved in the neonatal adaptation of the circulatory system, in osteoporosis, as well as in the initiation of skin immune responses $(12,13)$. As $N c f 2$ encodes a $67-\mathrm{kDa}$ cytosolic subunit of the multi-protein NADPH oxidase complex, its interaction with Ptger 4 has been implicated in a number of cardiovascular pathologies, such as atherosclerosis, hypertension and stroke (25).

Since these predicted interactions did not include most of the hypertension-related G-2 genes, we applied the IPA software, and suggested that G-1 and G-2 gene interactions are assisted by the presence of a gene. Agt, mutations of which are associated with susceptibility to essential hypertension, was found to aid the interactions between 2 G-1 and 4 G-2 genes (Fig. 1). These data suggest that Ptger4 is one of the candidate genes responsible for causing hypertension in SHR, and that $A l b$ and Cmal, in the presence of Agt, also behave as candidate genes causing hypertension in SHR by interacting with hypertension-related G-2 genes, such as Ncf2, Agtrlb, Agtrap and Snca (Fig. 1). 
Interactions among SHRSP-specific genes, and candidate genes responsible for causing stroke in SHRSP. Since candidate genes that cause stroke in SHRSP were expected to be included in the SHRSP-specific genes, we wished to determine the interactions between G-3 and G-4 genes (Fig. 2). IPA revealed 2 interactions: Agtrap not only interacted with Agtrlb, but also with Fos, which regulates the transcription from the RNA polymerase II promoter (Fig. 2). Moreover, Fos interacted with several other G-4 genes (Fig. 2). These results indicate that Agtrap and Fos play pivotal roles in the pathogenesis of stroke. All these interactions are expected to affect blood pressure, as Agtrap, Gclm, Agtrlb and Ephx2 were categorized by DAVID analysis into GO:0008015 (blood circulation) (Table II, G-4), and, using IPA, Agtrap, Agtrlb, Ephx2 and Ncf2 were functionally found to be involved in 'blood pressure' (Table V, G-4).

Genes possibly participating in the development of $A D H D$. Three G-2 genes were found to be involved in the uptake of norepinephrine'(Agtrap, Agtrlb and Snca) (Table V, G-2). Agtrap and Agtrlb were categorized into GO:0008015 (blood circulation), and Snca was categorized into GO:0006952 (defense response) (Table II, G-2). Snca regulates the homeostasis of dopaminergic and serotonergic synapses, through the trafficking of dopamine and serotonin transporters, and plays a central role in the homeostasis of noradrenergic neurons $(26,27)$. Accordingly, the SHR-specific G-2 genes involved in the 'uptake of norepinephrine' are expected not only to participate in the control of 'blood pressure', but also in the development of ADHD symptoms. Similarly, 4 G-4 genes, Agtrap, Agtrlb, Fos and Snca, were found to be involved in the 'uptake of norepinephrine' (Table V, G-4). Although Fos was not categorized using the enriched GO terms (Table IV-A), these 4 genes were expected to participate in 'blood pressure' control, and in the development of ADHD.

Six SHRSP-specific G-4 genes (Agtrlb, Arc, Egr2, Fos, $H$ spalb and $S n c a$ ), were found to be functionally involved in 'behavior' (Table V, G-4). Of note, 3 of these 6 genes, Agtrlb, Fos and Snca, were included among those functionally involved in the 'uptake of norepinephrine' (Table V, G-4). The remaining 3 genes, Arc, Egr2 and Hspalb, functionally involved in 'behavior', were also expected to participate in 'blood pressure' control, as well as in the development of ADHD. Arc plays a critical role in the consolidation of enduring synaptic plasticity and memory storage (28), while Egr2 encodes a transcription factor with 3 tandem $\mathrm{C} 2 \mathrm{H} 2$-type zinc fingers [since defects in this gene are associated with neurological diseases, such as Charcot-Marie-Tooth disease and Dejerine-Sottas syndrome, it has been suggested to play a role in learning and long-term potentiation $(29,30)]$. Hspalb encodes a 70-kDa heat-shock protein, which is known to promote neurodegeneration in sporadic Parkinson's disease through its functional interaction with other Parkinson's disease-related genes (31). All the aforementioned results suggest that not only the genes involved in the 'uptake of norepinephrine' but also those functionally involved in 'behavior' participate in the development of ADHD.

In conclusion, in this study, we analyzed the gene expression profiles in the brains of 3- and 6-week-old SHR and SHRSP, and found that the G-4 genes involved in the 'uptake of norepinephrine' include Agtrap, Agtrlb, Snca and Fos, and those related to 'blood pressure' include Agtrap, Agtrlb,
Ephx2 and Ncf2 (Table V, G-4). Moreover, Agtrlb, Snca, Fos, Arc, Egr2 and Hspalb were the genes involved in 'behavior' (Table V, G-4). Since Agtrap expression in SHRSP at 3 and 6 weeks of age interacted with Agtrlb (Fig. 2), these 2 genes participated not only in the 'uptake of norepinephrine' and 'blood pressure', but also in 'behavior'. These results reveal that Agtrap and Agtrlb participate in the development of hypertension and ADHD, indicating that there is a close association between hypertension and ADHD.

\section{Acknowledgements}

We would like to thank Dr Etsuro Yamanishi, President Emeritus of Hirakata General Hospital for Developmental Disorders, and Dr Aritomo Suzuki,Professor Emeritus of Kinki University, for their constant support and encouragement, and Miss Fumie Kanazawa for her expert secretarial assistance. We also thank the National Center for Biotechnology Information, USA, and DNA Data Bank of Japan for access to the network servers.

\section{References}

1. Okamoto K and Aoki K: Development of a strain of spontaneously hypertensive rats. Jpn Circ J 27: 282-293, 1963.

2. Okamoto K, Yamori Y and Nagaoka A: Establishment of the stroke-prone spontaneously hypertensive rat (SHR). Circ Res 34-35 (Suppl I): I143-I153, 1974.

3. Ueno KI, Togashi H, Mori K, et al: Behavioural and pharmacological relevance of stroke-prone spontaneously hypertensive rats as an animal model of a developmental disorder. Behav Pharmacol 13: 1-13, 2002 .

4. Faraone SV and Mick E: Molecular genetics of attention deficit hyperactivity disorder. Psychiatr Clin North Am 33: 159-180, 2010.

5. DasBanerjee T, Middleton FA, Berger DF, Lombardo JP, Sagvolden T and Faraone SV: A comparison of molecular alterations in environmental and genetic rat models of ADHD: a pilot study. Am J Med Genet B Neuropsychiatr Genet 147B: 1554-1563, 2008.

6. Russell VA, Oades RD, Tannock R, Killeen PR, Auerbach JG, Johansen EB and Sagvolden T: Response variability in AttentionDeficit/Hyperactivity Disorder: a neuronal and glial energetics hypothesis. Behav Brain Funct 2: 30, 2006.

7. Yamamoto H, Okuzaki D, Yamanishi K, et al: Genetic analysis of genes causing hypertension and stroke in spontaneously hypertensive rats. Int J Mol Med 31: 1057-1065, 2013.

8. Tajima A, Hans FJ, Livingstone D, Wei L, Finnegan W, DeMaro J and Fenstermacher J: Smaller local brain volumes and cerebral atrophy in spontaneously hypertensive rats. Hypertension 21: 105-111, 1993.

9. Lanari A, Silvestrelli G, De Dominicis P, Tomassoni D, Amenta F and Parnetti L: Arterial hypertension and cognitive dysfunction in physiologic and pathologic aging of the brain. Am J Geriatr Cardiol 16: 158-164, 2007.

10. Huang da W, Sherman BT and Lempicki RA: Systematic and integrative analysis of large gene lists using DAVID bioinformatics resources. Nat Protoc 4: 44-57, 2009.

11. Huang da W, Sherman BT and Lempicki RA: Bioinformatics enrichment tools: paths toward the comprehensive functional analysis of large gene lists. Nucleic Acids Res 37: 1-13, 2009.

12. Hoshino T, Namba T, Takehara M, et al: Prostaglandin E2 stimulates the production of amyloid-beta peptides through internalization of the EP4 receptor. J Biol Chem 284: 18493-18502, 2009.

13. Nguyen M, Camenisch T, Snouwaert JN, et al: The prostaglandin receptor EP4 triggers remodelling of the cardiovascular system at birth. Nature 390: 78-81, 1997.

14. Dickson ME, Tian X, Liu X, Davis DR and Sigmund CD: Upstream stimulatory factor is required for human angiotensinogen expression and differential regulation by the A-20C polymorphism. Circ Res 103: 940-947, 2008. 
15. Bakoush O, Tencer J, Torffvit O, Tenstad O, Skogvall I and Rippe B: Increased glomerular albumin permeability in old spontaneously hypertensive rats. Nephrol Dial Transplant 19: $1724-1731,2004$.

16. Frank BT, Rossall JC, Caughey GH and Fang KC: Mast cell tissue inhibitor of metalloproteinase-1 is cleaved and inactivated extracellularly by alpha-chymase. J Immunol 166: 2783-2792, 2001.

17. Azuma K, Tamura K, Shigenaga A, et al: Novel regulatory effect of angiotensin II type 1 receptor-interacting molecule on vascular smooth muscle cells. Hypertension 50: 926-932, 2007.

18. Matsuo K, Owens JM, Tonko M, Elliott C, Chambers TJ and Wagner EF: Fosl1 is a transcriptional target of c-Fos during osteoclast differentiation. Nat Genet 24: 184-187, 2000.

19. Gembardt F, Heringer-Walther S, van Esch JH, et al: Cardiovascular phenotype of mice lacking all three subtypes of angiotensin II receptors. FASEB J 22: 3068-3077, 2008.

20. Ishii $\mathrm{T}$, Onda $\mathrm{H}$, Tanigawa $\mathrm{A}$, et al: Isolation and expression profiling of genes upregulated in the peripheral blood cells of systemic lupus erythematosus patients. DNA Res 12: 429-439, 2005.

21. Beres TM, Masui T, Swift GH, Shi L, Henke RM and MacDonald RJ: PTF1 is an organ-specific and Notch-independent basic helix-loop-helix complex containing the mammalian Suppressor of Hairless (RBP-J) or its paralogue, RBP-L. Mol Cell Biol 26: 117-130, 2006.

22. Meredith DM, Masui T, Swift GH, MacDonald RJ and Johnson JE: Multiple transcriptional mechanisms control Ptfla levels during neural development including autoregulation by the PTF1-J complex. J Neurosci 29: 11139-11148, 2009.

23. Fukui $\mathrm{H}$, Miwa $\mathrm{E}$, Iwachido $\mathrm{T}$, Kitaura $\mathrm{H}$ and Furukawa $\mathrm{H}$ : Various emetogens increase the secretion of salivary amylase in rats: a potential model in emesis research. J Pharmacol Sci 113 143-152, 2010.

24. Asanuma-Date K, Hirano Y, Le N, et al: Functional regulation of sugar assimilation by $\mathrm{N}$-glycan-specific interaction of pancreatic $\alpha$-amylase with glycoproteins of duodenal brush border membrane. J Biol Chem 287: 23104-23118, 2012.

25. Ju W, Eichinger F, Bitzer M, et al: Renal gene and protein expression signatures for prediction of kidney disease progression. Am J Pathol 174: 2073-2085, 2009.

26. Wersinger C, Jeannotte A and Sidhu A: Attenuation of the norepinephrine transporter activity and trafficking via interactions with alpha-synuclein. Eur J Neurosci 24: 3141-3152, 2006.

27. Outeiro TF, Kontopoulos E, Altmann SM, et al: Sirtuin 2 inhibitors rescue alpha-synuclein- mediated toxicity in models of Parkinson's disease. Science 317: 516-519, 2007.

28. Plath N, Ohana O, Dammermann B, et al: Arc/Arg3.1 is essential for the consolidation of synaptic plasticity and memories. Neuron 52: 437-444, 2006.

29. Nagarajan R, Svaren J, Le N, Araki T, Watson M and Milbrandt J: EGR2 mutations in inherited neuropathies dominant-negatively inhibit myelin gene expression. Neuron 30: 355-368, 2001.

30. Zaman G, Sunters A, Galea GL, et al: Loading-related regulation of transcription factor EGR2/Krox-20 in bone cells is ERK1/2 protein-mediated and prostaglandin, Wnt signaling pathway- and insulin-like growth factor-I axis-dependent. J Biol Chem 287: 3946-3962, 2012.

31. Kalia SK, Lee S, Smith PD, et al: BAG5 inhibits parkin and enhances dopaminergic neuron degeneration. Neuron 44: 931-945, 2004.

32. Soupene E and Kuypers FA: Mammalian long-chain acyl-CoA synthetases. Exp Biol Med (Maywood) 233: 507-521, 2008.

33. Boomgaarden I, Vock C, Klapper M and Döring F: Comparative analyses of disease risk genes belonging to the acyl-CoA synthetase medium-chain (ACSM) family in human liver and cell lines. Biochem Genet 47: 739-748, 2009.

34. Barouk S, Hintz T, Li P, Duffy AM, MacLusky NJ and Scharfman HE: $17 \beta$-estradiol increases astrocytic vascular endothelial growth factor (VEGF) in adult female rat hippocampus. Endocrinology 152: 1745-1751, 2011.
35. Ohno K, Brengman J, Tsujino A and Engel AG: Human endplate acetylcholinesterase deficiency caused by mutations in the collagen-like tail subunit (ColQ) of the asymmetric enzyme. Proc Natl Acad Sci USA 95: 9654-9659, 1998.

36. Park JA, Drazen JM and Tschumperlin DJ: The chitinase-like protein YKL-40 is secreted by airway epithelial cells at base line and in response to compressive mechanical stress. J Biol Chem 285: 29817-29825, 2010.

37. David SP, Hamidovic A, Chen GK, et al: Genome-wide metaanalyses of smoking behaviors in African Americans. Transl Psychiatry 2: e119, 2012.

38. Bièche I, Latil A, Parfait B, et al: CGA gene (coding for the alpha subunit of glycoprotein hormones) overexpression in ER alphapositive prostate tumors. Eur Urol 41: 335-341, 2002.

39. Nakamura S, Sugiyama S, Fujioka D, Kawabata K, Ogawa H and Kugiyama K: Polymorphism in glutamate-cysteine ligase modifier subunit gene is associated with impairment of nitric oxide-mediated coronary vasomotor function. Circulation 108: 1425-1427, 2003

40. Sinal CJ, Miyata M, Tohkin M, Nagata K, Bend JR and Gonzalez FJ: Targeted disruption of soluble epoxide hydrolase reveals a role in blood pressure regulation. J Biol Chem 275: 40504-40510, 2000.

41. Feuser K, Thon KP, Bischoff SC and Lorentz A: Human intestinal mast cells are a potent source of multiple chemokines. Cytokine 58: 178-185, 2012.

42. Damiano BP, Cheung WM, Santulli RJ, et al: Cardiovascular responses mediated by protease-activated receptor-2 (PAR-2) and thrombin receptor (PAR-1) are distinguished in mice deficient in PAR-2 or PAR-1. J Pharmacol Exp Ther 288: 671-678, 1999.

43. Ma G, Pan PY, Eisenstein S, Divino CM, Lowell CA, Takai T and Chen SH: Paired immunoglobin-like receptor-B regulates the suppressive function and fate of myeloid-derived suppressor cells. Immunity 34: 385-395, 2011.

44. Crajoinas RO, Lessa LM, Carraro-Lacroix LR, et al: Posttranslational mechanisms associated with reduced NHE3 activity in adult vs. young prehypertensive SHR. Am J Physiol Renal Physiol 299: F872-F881, 2010.

45. Klaus F, Palmada M, Lindner R, Laufer J, Jeyaraj S, Lang F and Boehmer C: Up-regulation of hypertonicity-activated myoinositol transporter SMIT1 by the cell volume-sensitive protein kinase SGK1. J Physiol 586: 1539-1547, 2008.

46. Lang F, Huang DY and Vallon V: SGK, renal function and hypertension. J Nephrol 23 (Suppl 16): S124-S129, 2010.

47. Loffing J, Flores SY and Staub O: Sgk kinases and their role in epithelial transport. Annu Rev Physiol 68: 461-490, 2006.

48. Tanabe Y, Hirano A, Iwasato T, et al: Molecular characterization and gene disruption of a novel zinc-finger protein, HIT-4, expressed in rodent brain. J Neurochem 112: 1035-1044, 2010.

49. Martínéz-Jiménez CP, Castell JV, Gómez-Lechón MJ and Jover R: Transcriptional activation of $C Y P 2 C 9, C Y P 1 A 1$, and $C Y P 1 A 2$ by hepatocyte nuclear factor 4alpha requires coactivators peroxisomal proliferator activated receptor-gamma coactivator 1alpha and steroid receptor coactivator 1. Mol Pharmacol 70: 1681-1692, 2006.

50. Suzuki T, Onogawa T, Asano N, et al: Identification and characterization of novel rat and human gonad-specific organic anion transporters. Mol Endocrinol 17: 1203-1215, 2003.

51. Kato M, Neil TK, Clark GJ, Morris CM, Sorg RV and Hart DN: cDNA cloning of human DEC-205, a putative antigen-uptake receptor on dendritic cells. Immunogenetics 47: 442-450, 1998.

52. Jonassen $\mathrm{T}$ and Clarke CF: Isolation and functional expression of human COQ3, a gene encoding a methyltransferase required for ubiquinone biosynthesis. J Biol Chem 275: 12381-12387, 2000.

53. Sutherland AP, Zhang H, Zhang Y, et al: Zinc finger protein Zbtb20 is essential for postnatal survival and glucose homeostasis. Mol Cell Biol 29: 2804-2815, 2009.

54. Cao Y, Pahlberg J, Sarria I, Kamasawa N, Sampath AP and Martemyanov KA: Regulators of G protein signaling RGS7 and RGS11 determine the onset of the light response in ON bipolar neurons. Proc Natl Acad Sci USA 109: 7905-7910, 2012. 